\title{
Morphological and molecular characterization of recombinant inbred lines for dormancy related traits in rice (Oryza sativa L.)
}

\author{
D. B. K. V. Mani*, B. Krishna Veni, V. Roja and S. N. Umar \\ Department of Genetics and Plant Breeding, Agricultural College, Bapatla (A.P.) India
}

(Email: balakanaka95@gmail.com)

\begin{abstract}
The study was carried out to assess the genetic relatedness of 119 recombinant inbred lines along with their parents BPT 2231 and MTU 1001 based on morphological and molecular characterization. Data recorded for 10 morphological characters was used for grouping genotypes into different clusters by using Tocher's and UPGMA dendrogram methods. Under $\mathrm{D}^{2}$ analysis, the genotypes were grouped into 6 clusters and out of 10 characters studied, free amino acids contributed maximum divergence followed by days to $50 \%$ flowering and test weight. The genotypes grouped in cluster III recorded strong dormancy both at 5 days and 10 days after harvesting whereas the genotypes of cluster IV recorded maximum grain yield/plant. Four polymorphic markers were used for genotyping of the RIL population and the lines viz., SD 3, SD 12, SD 15, SD 68, SD 72, SD 87 and SD 113 which were categorized as strongly dormant upto 10 days after harvesting also exhibited similar banding pattern with the dormant parent MTU 1001 when amplified with more than two markers. Among the 119 RIL population studied, SD 12 manifested banding pattern as that of the dormant parent MTU 1001 with all the four polymorphic markers viz., RM346, RM22565, RM7051 and RM10793 under study and also exhibited $<10 \%$ germination at 10 days after harvesting. The number of alleles detected for each of the 4 polymorphic markers ranged from 2 to 4 per loci with mean value of 2.75 alleles per locus. The dendrogram analysis divided the entire population into two distinct clusters at the distance of 2.25. The RILs viz., SD11, SD12, SD15, SD27, SD30, SD63, SD65, SD68, SD74, SD75, SD80 along with the dormant parent MTU 1001(SD 121) which recorded less than 50\% germination and categorized as strongly dormant under phenotyping were grouped in cluster IB2 in molecular analysis thus revealing the similarity between the two methods.
\end{abstract}

Key Words : Recombinant inbred lines, $\mathrm{D}^{2}$ analysis, UPGMA dendrogram

View Point Article : Mani, D. B. K. V., Krishna Veni, B., Roja, V. and Umar, S. N. (2021). Morphological and molecular characterization of recombinant inbred lines for dormancy related traits in rice (Oryza sativa L.). Internat. J. agric. Sci., 17 (AAEBSSD) : 41-50, DOI:10.15740/ HAS/IJAS/17-AAEBSSD/41-50. Copyright@2021: Hind Agri-Horticultural Society.

Article History : Received : 09.07.2021; Accepted : 14.07.2021

\section{INTRODUCTION}

Rice is one of the predominant food crops of the world and pre-harvest sprouting (PHS) is a major constraint to the production of high quality grain in humid climate. Genetic variation for tolerance to PHS is

\footnotetext{
* Author for correspondence :
} 
associated with seed dormancy. Varieties having a low level of seed dormancy often show pre-harvest sprouting in rainy \& humid climates and highly influenced by environmental factors (Seshu and Sorrells 1986, Li and Foley 1997, Cai and Morishima 2000). The long term solution to pre-harvest sprouting relies on the development of cultivars that are able to tolerate the damaging effects of rain during the period between maturity and the completion of harvest (Li et al., 2004). As this trait is highly influenced by climatic factors, screening of cultivars and selection on the basis of phenotype is problematic. Therefore molecular markers linked to genes associated with pre-harvest sprouting resistance could be useful tool in marker assisted selection in order to develop the cultivars with resistance to pre-harvest sprouting. Before launching any breeding programme, in addition to the knowledge on seed dormancy and PHS of germplasm lines, a thorough knowledge on the nature and magnitude of genetic variability among germplasm lines for yield and yield components is essential. The quantification of degree of divergence in a given material is of immense value in identification of divergent genotypes for further use in hybridization to create new variability. Keeping the above points in view, the present investigation was carried out with the objective to estimate the genetic relatedness of RIL population through morphological and molecular analysis.

\section{Material AND Methods}

The material comprising of 119 recombinant inbred lines (SD 1 to SD 119) from a cross between BPT 2231 and MTU 1001 were grown in simple lattice design with two replications at Agricultural College Farm, Bapatla during kharif 2018-19. Each experimental unit consisted of $2.4 \mathrm{~m}^{2}$ and the spacing adopted was $20 \mathrm{~cm}$ between rows and $15 \mathrm{~cm}$ between plants. All the recommended package of practices were followed during the crop growth and data was collected on five randomly selected plants in each replication for 6 yield components, 2 dormancy related traits and 2 physiological parameters viz., days to $50 \%$ flowering, productive tillers per plant, plant height, panicle length, test weight, grain yield per plant, germination (\%) at 5 days after harvesting, germination (\%) at 10 days after harvesting, free amino acids and total soluble sugars. The germination (\%) at 5 days and 10 days after harvesting was assessed by following the procedure delineated by Wan et al. (1997).
After calculating the germination (\%) of RIL population they were categorized into different dormancy groups as weakly dormant $(>80 \%)$, moderately dormant (50$79 \%)$ and strongly dormant $(<50 \%)$ and the time taken for attaining $80 \%$ germination after maturity was considered as the duration of dormancy as suggested by Voleti et al., 2013. The physiological parameters viz., free amino acids and total soluble sugars were estimated by following the prescribed protocol of Moore and Stein (1948) and Hedge and Hofreiter (1962) respectively. The mean data obtained was used to determine the genetic diversity among the genotypes using Mahalanobis $\mathrm{D}^{2}$ statistic as per Rao (1952) and cluster analysis as described by Anderson (1993).

\section{Molecular analysis :}

The DNA of entire RIL population along with parents was isolated from young leaves harvested after 15 days of sowing using C-TAB method as described by Doyle and Doyle (1990). The PCR was carried out using a programmable thermocycler (Eppendorf, Germany). The PCR plates were taken and $2.5 \mu 1$ of $50 \mathrm{ng}$ template DNA was pipetted out into each of the PCR tubes after proper labeling and kept the PCR plate at $4^{0} \mathrm{C}$. Master mix was prepared by taking each $1 \mu \mathrm{l}$ of $10 \mathrm{pmol}$ primer (both forward and reverse primer), $0.5 \mu \mathrm{l}$ of $2.5 \mathrm{mM}$ deoxyribonucleotides (dNTPs), $1 \mu$ of Genei 10X assay buffer (10 mM Tris $\mathrm{HCl}$ (pH 8.3), $50 \mathrm{mM} \mathrm{KCl}, 1.5 \mathrm{mM}$ $\mathrm{MgCl} 2,0.01 \%$ gelatin) and $1 \mu \mathrm{l}$ of $1 \mathrm{U} / \mu \mathrm{T}$ Taq DNA polymerase (Banglore Genei Private Limited, Bangalore) and $3 \mu \mathrm{l}$ of sterile distilled water was added to make up the volume to $10 \mu \mathrm{l}$ was subjected to the polymerase chain reaction. Four polymorphic markers were used to reveal the genetic diversity among the RILs. The profile of PCR was followed: $94^{\circ} \mathrm{C}$ for 5 minutes (Initial denaturation), $94^{\circ} \mathrm{C}$ for 30 seconds (Final denaturation), $55^{\circ} \mathrm{C}$ for 30 seconds (Annealing), $72^{\circ} \mathrm{C}$ for 1 minute (Extension) and $72^{\circ} \mathrm{C}$ for 7 minute (Final extension). A $3 \%$ agarose gel was prepared and the PCR product was visualized under UV light transmitted gel documentation system presented in Fig. 1 (Alpha Infotech, USA). The clearly resolved amplicons of SSR were scored manually as presence and absence of band. The code 1 was given for the genotype if a band is present otherwise 0 code for the absence of the band in the data sheet. This recorded data was utilized to construct the dendrogram for cluster analysis using past 3 software version $2.17 \mathrm{C}$. 
Morphological \& molecular characterization of recombinant inbred lines for dormancy related traits in rice

\section{RESUlts AND Discussion}

The analysis of variance showed that the mean sum of squares for the genotypes were highly significant for all the characters under study suggesting the presence of sufficient variability among the materials under study. Based on the phenotyping results and duration of dormancy, among the 119 RIL's under study, 34 lines are strongly dormant while 42 lines were moderately dormant for 10 days after harvesting (Table 1). Among these, SD 3,15,17,20,30,32,65,76 and SD 80 recorded significantly superior grain yield than the parents and hence can be utilized as a promising cultures in future breeding programmes (Table 2). The line, SD 12 recorded less than $10 \%$ germination even at 10 days after harvesting, hence can be utilized as donor after further testing. The results of $\mathrm{D}^{2}$ analysis showed the presence of considerable variability among the RIL population under study. The genotypes were grouped into 6 clusters and maximum number of genotypes (86) were grouped in cluster I followed by cluster II with 18 genotypes (Table 3). Cluster V and VI are solitary clusters with no intra-cluster distance. Per cent contribution of each character is calculated on the basis of occurrence of ranks and is presented in the table 4 . Out of 10 characters studied, free amino acids (35.58\%) contributed maximum divergence among the RIL population suggesting that the population consists of genotypes with high as well as low amino acid content which directly influence the germination percentage. Days to $50 \%$ of flowering $(22.09 \%)$ and test weight $(15.55 \%)$ also contributed towards divergence which are in agreement with the findings of Monohara and Singh (2013) and Kumar et al. (2015). The average intra-cluster distance ranged from (cluster V and VI) 0.0 to 623.05 (cluster IV) and maximum inter-cluster distance (2433.35) was found between cluster II and cluster VI indicating wide diversity between these clusters (Table 5) indicating that the genotypes of these clusters had maximum number of

\begin{tabular}{|c|c|c|c|c|}
\hline Sr. No. & $\begin{array}{c}\text { Scale of } \\
\text { dormancy }\end{array}$ & $\begin{array}{c}\text { Germination } \\
(\%)\end{array}$ & $\begin{array}{c}\text { Number of } \\
\text { lines }\end{array}$ & Designation of the RIL population \\
\hline 1. & \multirow{5}{*}{$\begin{array}{l}\text { Strongly } \\
\text { dormant }\end{array}$} & 0 to $10 \%$ & 1 & SD 12 \\
\hline 2. & & 11 to $20 \%$ & 0 & Nil \\
\hline 3. & & 21 to $30 \%$ & 12 & $\begin{array}{l}\text { SD 3, SD 15, SD 24, SD 32, SD 63, SD 65, SD 71, SD 81, SD 87, SD 1 13, SD 117, SD } \\
121 \text { (MTU 1001) }\end{array}$ \\
\hline 4. & & 31 to $40 \%$ & 10 & SD 20, SD 21, SD 30, SD 31, SD 45, SD 59, SD 68, SD 75, SD 76, SD 80 \\
\hline 5. & & 41 to $50 \%$ & 11 & SD 7, SD 11, SD 17, SD 27, SD 35, SD 47, SD 49, SD 72, SD 90, SD 92, SD 104 \\
\hline 6. & \multirow{3}{*}{$\begin{array}{c}\text { Moderately } \\
\text { dormant }\end{array}$} & 51 to $60 \%$ & 11 & SD 16, SD 50, SD 51, SD 57, SD 64, SD 69, SD 74, SD 95, SD 96, SD 99, SD 118 \\
\hline 7. & & 61 to $70 \%$ & 16 & $\begin{array}{l}\text { SD } 6 \text {, SD 13, SD 14, SD 18, SD 22, SD 33, SD 38, SD 67, SD 77, SD 79, SD 89, SD 94, } \\
\text { SD 106, SD 110, SD 112, SD } 116\end{array}$ \\
\hline 8. & & 71 to $80 \%$ & 15 & $\begin{array}{l}\text { SD 1, SD 2, SD 19, SD 25, SD 29, SD 37, SD 42, SD 48, SD 53, SD 58, SD 62, SD 70, } \\
\text { SD 84, SD 85, SD } 105\end{array}$ \\
\hline 9. & \multirow{2}{*}{$\begin{array}{l}\text { Weakly } \\
\text { dormant }\end{array}$} & 81 to $90 \%$ & 27 & 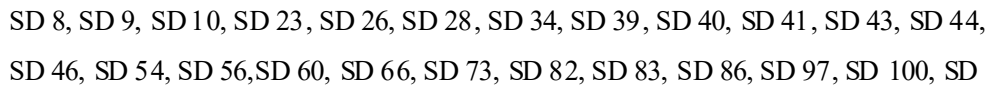 \\
\hline 10. & & 91 to $100 \%$ & 18 & $\begin{array}{l}\text { 107, SD 108, SD 111, SD } 114 \\
\text { SD 4, SD 5, SD } 36, \text { SD 52, SD 55, SD 61, SD 78, SD 88, SD 91, SD 93, SD 98, SD 101, } \\
\text { SD 102, SD 103, SD 109, SD 115, SD 119, SD } 120 \text { (BPT 2231) }\end{array}$ \\
\hline
\end{tabular}

\begin{tabular}{llc}
\hline \multicolumn{2}{l}{ Table 2: Mean \pm SE of parents and RIL's for grain yield in rice (Oryza sativa L.) } \\
\hline Sr. No. & Parents/RIL's & Grain yield per plant $(\mathrm{g})$ \\
\hline 1. & Non dormant Parent ( BPT 2231) & $32.55 \pm 6.152$ \\
2. & Dormant parent (MTU 1001) & $31.50 \pm 3.535$ \\
3. & RIL population (Progeny) & $32.26 \pm 0.496$ \\
4. & Standard deviation of the progeny & 5.461 \\
\hline
\end{tabular}


D. B. K. V. Mani, B. Krishna Veni, V. Roja and S. N. Umar

gene complexes, while minimum distance (792.37) was found between cluster I and cluster IV.

The cluster mean values for different traits under study were presented in Table 6 . Among the six clusters, cluster IV recorded maximum days for $50 \%$ flowering suggesting that the genotypes with longer duration were grouped in this cluster. The genotypes with dwarf stature coupled with early duration and more number of ear bearing tillers were grouped in cluster VI. Maximum panicle length $(25.4 \mathrm{~cm})$ was manifested by the genotypes grouped in cluster II while the genotypes in cluster III had maximum test weight (21.78 g). Among the RIL population under study, slender genotypes possessing lower test weight were grouped in cluster VI. All the RILs grouped in cluster VI exhibited maximum germination (\%) both at 5 days and 10 days after harvesting indicating that their dormancy levels are low and they are not suitable for cultivation under humid

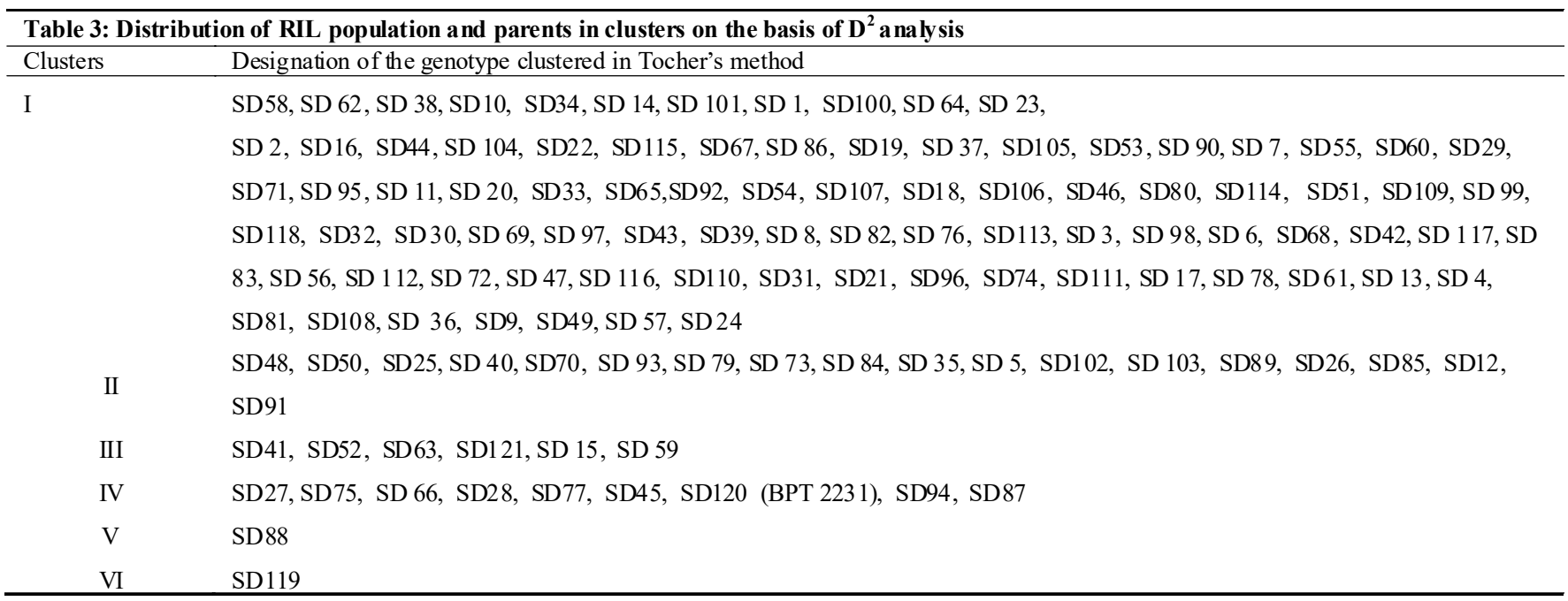

\begin{tabular}{lcc}
\hline Table 4: Relative cont ribution (\%) of individual trait to the divergence among genotypes & No. of times ranked first & Contribution (\%) \\
\hline Character/Trait & 1604 & $22.09 \%$ \\
\hline Days to 50\% flowering (No.) & 64 & $0.88 \%$ \\
Number of ear bearing tillers (No.) & 208 & $2.87 \%$ \\
Plant height (cm) & - & - \\
Panicle length (cm) & 1129 & $15.55 \%$ \\
Test weight (g) & - & - \\
Grain yield per plant (g) & 207 & $2.85 \%$ \\
Germination (\%) at 5 days after harvesting & 460 & $6.34 \%$ \\
Germination (\%) at 10 days after harvesting & 2583 & $35.58 \%$ \\
Free amino acids (mg/100g) & 1005 & $13.84 \%$ \\
Total soluble sugars (mg/100g) & & \\
\hline
\end{tabular}

\begin{tabular}{|c|c|c|c|c|c|c|}
\hline Clusters & $\mathrm{I}$ & II & III & IV & $\mathrm{V}$ & $\mathrm{VI}$ \\
\hline I & 424.46 & 896.26 & 879.96 & 792.37 & 1039.44 & 1720.57 \\
\hline II & & 542.65 & 1458.78 & 1269.56 & 849.31 & 2433.35 \\
\hline III & & & 617.42 & 1824.9 & 1332.15 & 1676.88 \\
\hline IV & & & & 623.05 & 1304.06 & 1939.48 \\
\hline V & & & & & 0 & 827.86 \\
\hline VI & & & & & & 0 \\
\hline
\end{tabular}


Morphological \& molecular characterization of recombinant inbred lines for dormancy related traits in rice

\begin{tabular}{|c|c|c|c|c|c|c|c|c|c|c|}
\hline \multirow{2}{*}{ Cluster No. } & \multirow{2}{*}{ DFF } & \multirow{2}{*}{ EBT } & \multirow{2}{*}{ P.H } & \multirow{2}{*}{ P.L } & \multirow{2}{*}{ T. W } & \multicolumn{2}{|c|}{ Germination (\%) } & \multirow{2}{*}{ FAA } & \multirow{2}{*}{ TSS } & \multirow{2}{*}{ GY/P } \\
\hline & & & & & & 5DAH & $10 \mathrm{DAH}$ & & & \\
\hline Cluster I & 108.54 & 11.00 & 112.93 & 25.35 & 21.71 & 42.71 & 64.98 & 1.64 & 19.76 & 32.64 \\
\hline Cluster II & 107.67 & 11.66 & 111.78 & 25.47 & 21.66 & 56.67 & 74.44 & 3.34 & 22.21 & 30.44 \\
\hline Cluster III & 100.58 & 11.58 & 107.68 & 25.35 & 21.78 & 32.25 & 49.58 & 1.36 & 22.35 & 32.59 \\
\hline Cluster IV & 114.61 & 11.61 & 107.97 & 25.03 & 20.32 & 41.33 & 59.28 & 1.78 & 16.08 & 34.18 \\
\hline Cluster V & 105.50 & 11.15 & 107.85 & 24.80 & 17.30 & 59.00 & 93.00 & 2.80 & 25.45 & 23.75 \\
\hline Cluster IV & 104.00 & 12.50 & 89.65 & 19.30 & 15.80 & 95.00 & 98.00 & 0.95 & 25.40 & 24.30 \\
\hline
\end{tabular}

climate. The genotypes grouped in cluster III recorded strong dormancy both at 5 days and 10 days after harvesting whereas the genotypes of cluster IV and cluster I are strongly dormant upto 5 days after harvesting. Maximum grain yield/plant (34.18 g) was exhibited by the genotypes of cluster IV followed by cluster I and III. The genotypes grouped in cluster III were strongly dormant for 10 days after harvesting which recorded high grain yield also hence, these genotypes may be tested for their suitability in coastal areas during Kharif season. The genotypes in cluster II manifested desirable mean value for majority of the characters studied and these genotypes would be utilized in hybridization programme for transfer of desirable genes.

A total of 118 SSR markers were used for polymorphic survey between dormant and non-dormant parent and 10 out of them showed polymorphism among the parents. These 10 polymorphic markers were used for genotyping of the entire RIL population. All markers showed clear amplification and out of 10 SSRs, four polymorphic primers (RM346, RM22565, RM7051 and RM10793) were used to study their possible association with dormancy. Segregation pattern with marker RM 346 showed a high dormancy allele similar to that of donor in 43 plants and low dormancy allele of recipient was amplified in 47 lines (Fig. 1). Similarly, with RM 22565 marker, 67 lines showed donor allele and 52 lines manifested recipient allele (Fig. 2). The marker RM 7051 recorded 57 lines having similar alleles as that of dormant parent MTU 1001 and 58 lines showed similar amplicon size of non-dormant parent BPT 2231. Likewise, the amplification pattern of RM 10793 marker revealed that 67 lines manifested similar alleles to that of the dormant parent, while 42 lines reported similar alleles as that of non dormant parent BPT 2231.

Among the RIL population under study, three lines viz., SD 3, SD 15 and SD 113 manifested similar amplicon size with the dormant parent MTU 1001 when amplified with two markers viz., RM346 and RM7051. Likewise, three lines viz., SD 55, SD 68 and SD 72 exhibited similar banding pattern with MTU1001 when amplified with RM346 and RM22565. The line SD113 also manifested similar banding pattern with that of MTU 1001 when it was amplified with 3 markers viz., RM346, RM22565 and RM7051 while SD 72 and SD 87 exhibited similar bands with RM346, RM22565 and RM10793. Among the 119 RIL population studied, one line i.e. SD 12 manifested banding pattern as that of the dormant parent MTU 1001 with all the four polymorphic markers viz., RM346, RM22565, RM7051 and RM10793. In phenotyping also, SD 12 recorded only $10 \%$ germination at 10 days after harvesting whereas the dormant parent exhibited $25 \%$ germination at 10 days after harvesting.

A wide range of amplicon sizes were observed ranging from 135 to $220 \mathrm{bp}$. The number of alleles detected for each of the 4 markers ranged from 2 to 4 per loci with mean value of 2.75 alleles per locus. The PIC value for 4 SSR loci in our study varied from 0.5 (RM7051 and RM10793) to 0.62 (RM346) with an average of 0.56 (Table 7). The estimated average PIC values are relatively higher for markers RM 346 and RM 22565 than the average PIC values reported as 0.56 and this might be due to higher genetic diversity present in the population under study. Markers with PIC values of 0.5 or higher are highly informative for genetic studies and are extremely useful in distinguishing the polymorphism rate of a marker at a specific locus (Virk et al., 1995). Bharathi et al. (2019) in a study involving 32 rice genotypes for dormancy reported the PIC ranging from 0.67 (RM480) to 0.79 (RM252) with a mean value of 0.74 . The amount of polymorphism reflects the existence of considerable difference in their loci among the genotypes tested for the trait of interest. In a similar study by Sunayana et al. (2014) also tested 120 microsatellite markers for dormancy in 100 genotypes and a total of 124 alleles were detected with an average 


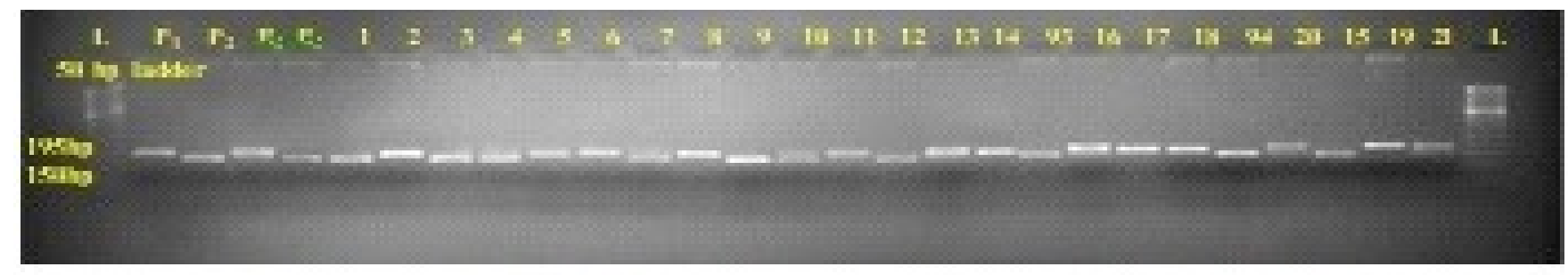

a) P1-BPT 2231; P2-MTU 1001; RII's from SD 1 - SD 21

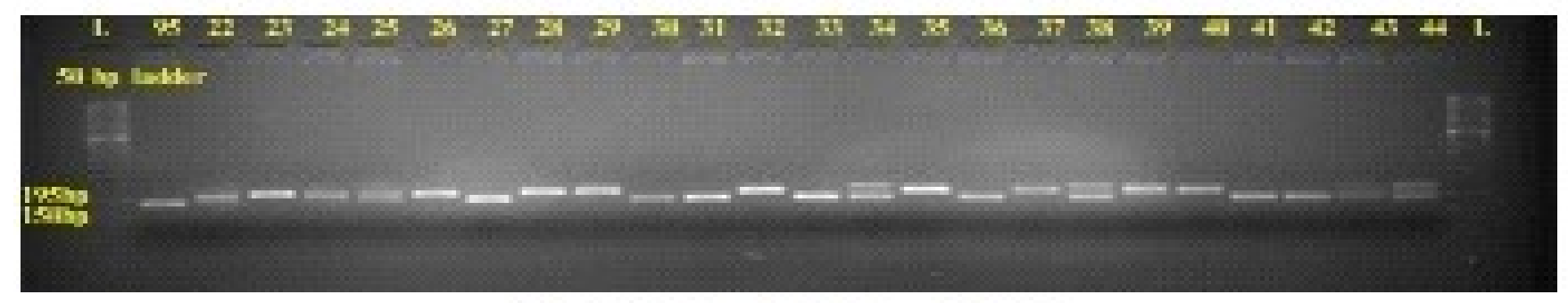

b) $\mathrm{FII} / \mathrm{f}$ from $\mathrm{SD} 22-\mathrm{SD} 44$

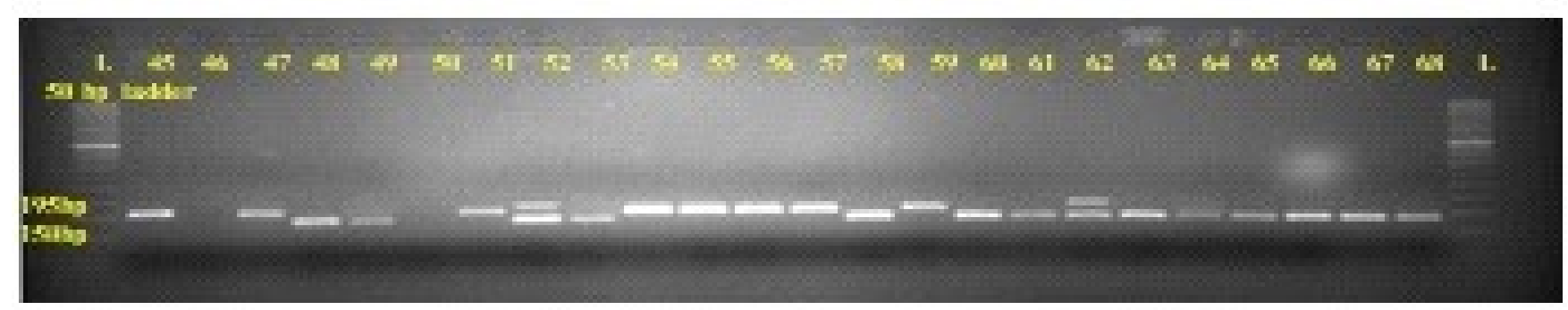

C) RIL's from SD $45-5 D 68$

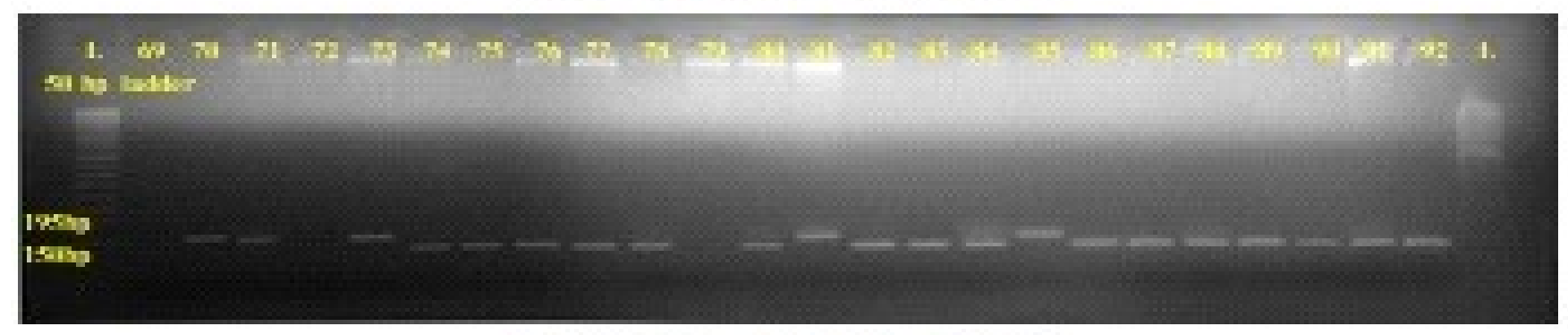

d) FIL's from SD $69-5 \mathrm{D} 92$

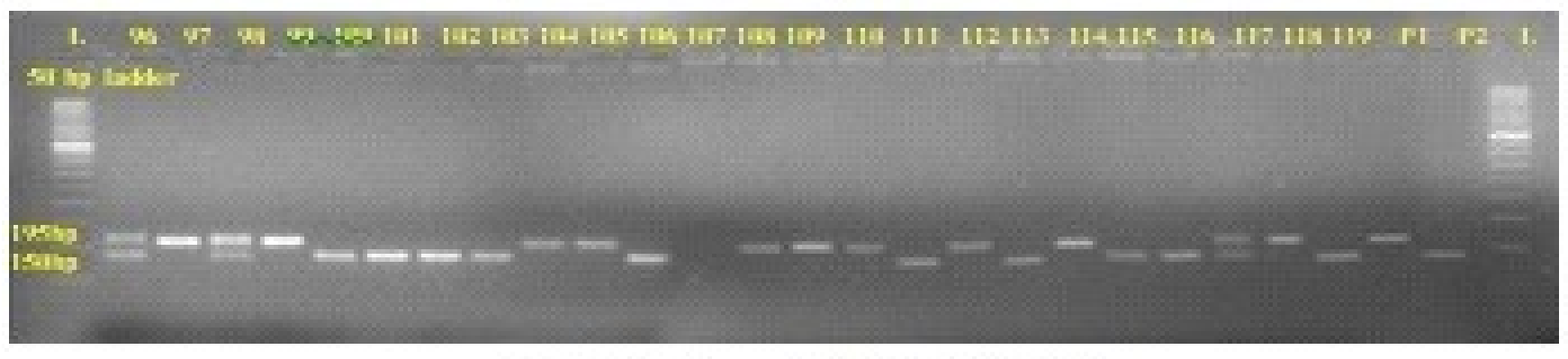

e) RII from SD 96-SD 119

Fig. 1: Genotyping of RIL population using marker RM 346 


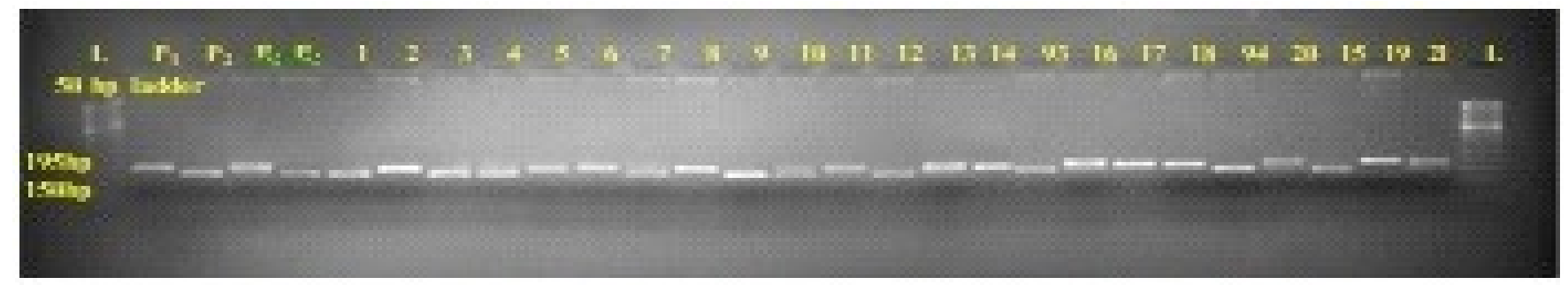

a) P1-BPT 2231; P2-MTU 1001; RII's from SD 1 - SD 21

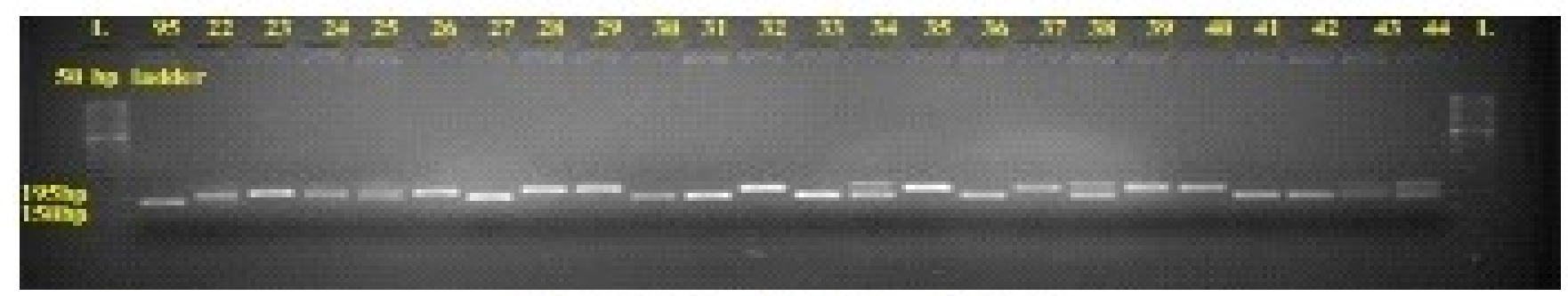

b) $\mathrm{FIL}$ ' from $\mathrm{SD} 22-\mathrm{SD} 44$

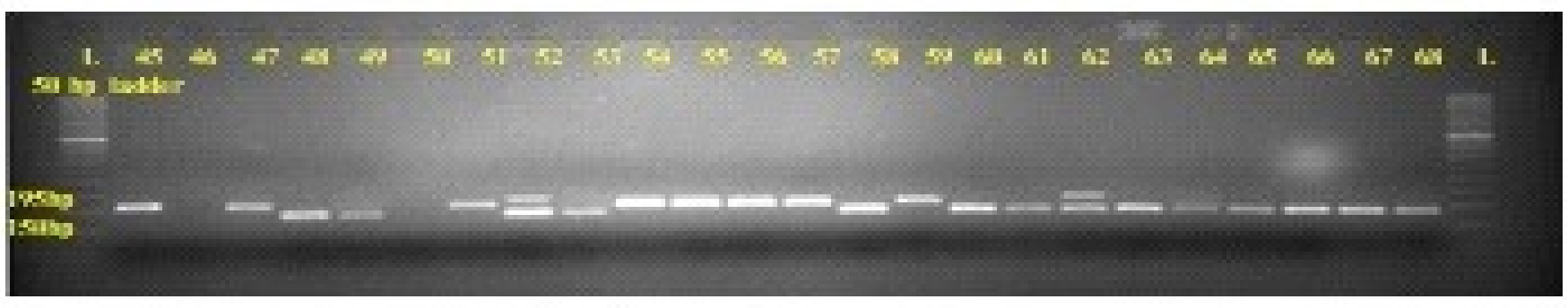

C) RIL' from SD $45-\mathrm{SD} 68$

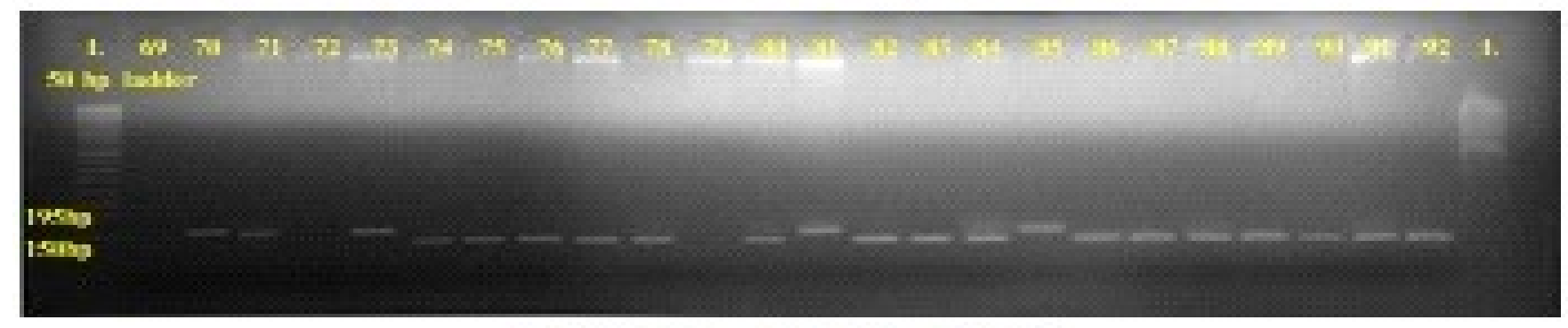

d) RII's from SD $69-\mathrm{SD} 92$

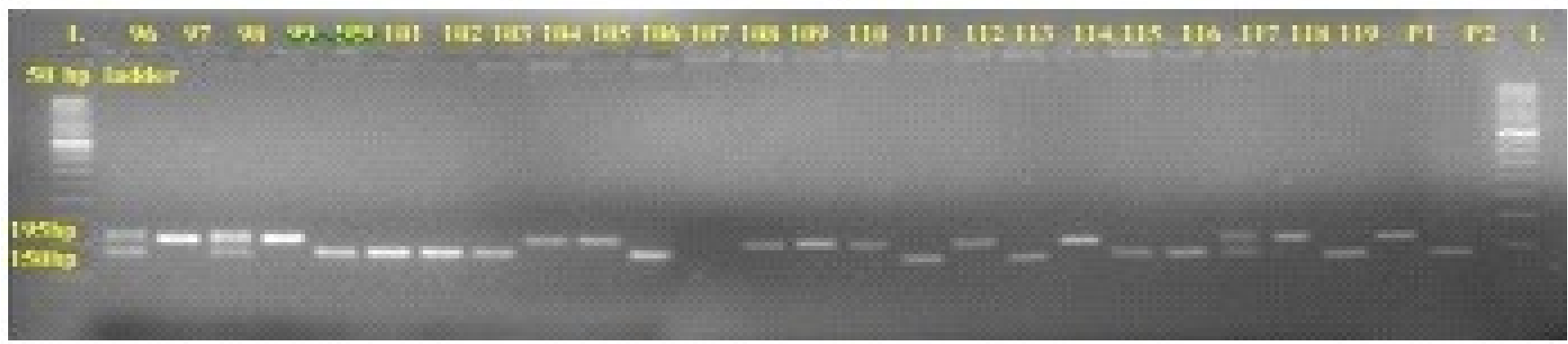

e) RII's from SD 96-SD 119

Fig. 2 : Genotyping of RIL population using marker RM 22565

Internat. J. agric. Sci. $\mid$ Jan., $2021 \mid$ Vol. $17 \mid$ Issue $1 \mid 41-50$ H 47 Hind Agricultural Research and Training Institute 
D. B. K. V. Mani, B. Krishna Veni, V. Roja and S. N. Umar

\begin{tabular}{llccc}
\hline \multicolumn{2}{l}{ Table 7: Parental polymorphism and PIC values of 4 SSR markers } & & \\
\hline Sr. No. & Name of the Primer & Total no. of bands & Percen tage of polymorphism & PIC \\
\hline 1. & RM346 & 4 & 100 & 0.62 \\
2. & RM22565 & 4 & 100 & 0.60 \\
3. & RM7051 & 2 & 100 & 0.50 \\
4. & RM10793 & 2 & 100 & 0.50 \\
& Mean & - & - & 0.56 \\
\hline
\end{tabular}

of 1.867 alleles per locus ranging from one (RM17, RM345, RM234) to three (RM592).

The data of molecular markers scored for each primer was analyzed to generate dendrogram (Fig.3) by using PAST software. The entire population (121 lines) was grouped into two distinct clusters at the distance of 2.25. The main Cluster I and II are sub divided into IA, IB and IIA and IIB respectively. The sub cluster IB and IIA again divided into IB1 and IB2 and IIA1 and IIA2 clusters. Here, the sub cluster IIA2 divided into IIA2.1 and IIA2.2 (Table 8). The dendrogram presented that the cluster I having subdivision IA $(111,90)$ recorded higher cluster difference with the cluster II having sub cluster IIB (91, 96, 110 and 81). Similar results were reported by Pervaiz et al. (2010) when they worked on 75 genotypes of rice land races and identified greater diversity among genotypes with similarity coefficient of 0.40 .

Molecular studies represent the actual genotypic containments and are independent of environment. When both the methods were compared, it was observed that the lines viz., SD11, SD12, SD15, SD27, SD30, SD63, SD65, SD68, SD74, SD75, SD80 and SD 92 categorized as strongly dormant upto 10 days after harvesting were grouped in IIA cluster along with the dormant parent MTU 1001 under molecular analysis revealing strong correlation between morphological and molecular analysis. The genotypes grouped in cluster I under $\mathrm{D}^{2}$ analysis are divided into 5 sub clusters viz., Cluster IB1, ClusterIB2, Cluster IIA, Cluster IIA2.1 and Cluster IIA2.2in molecular diversity analysis indicating molecular studies can divide the genotypes precisely than the diversity based on morphological characters. Among the RIL population grouped in cluster I under $\mathrm{D}^{2}$ analysis, 30 genotypes viz., SD 3,6,9,11,15,16,17,20,29.30,32,34, $36,37,46,60,65,67,76,80,83,86,95,105,61,107,109,115,116$ and 118 recorded significant yield superiority than the parents. Under molecular diversity, all these genotypes were grouped in 5 sub clusters viz., Cluster IB1, ClusterIB2, Cluster IIA, Cluster IIA2.1 and Cluster

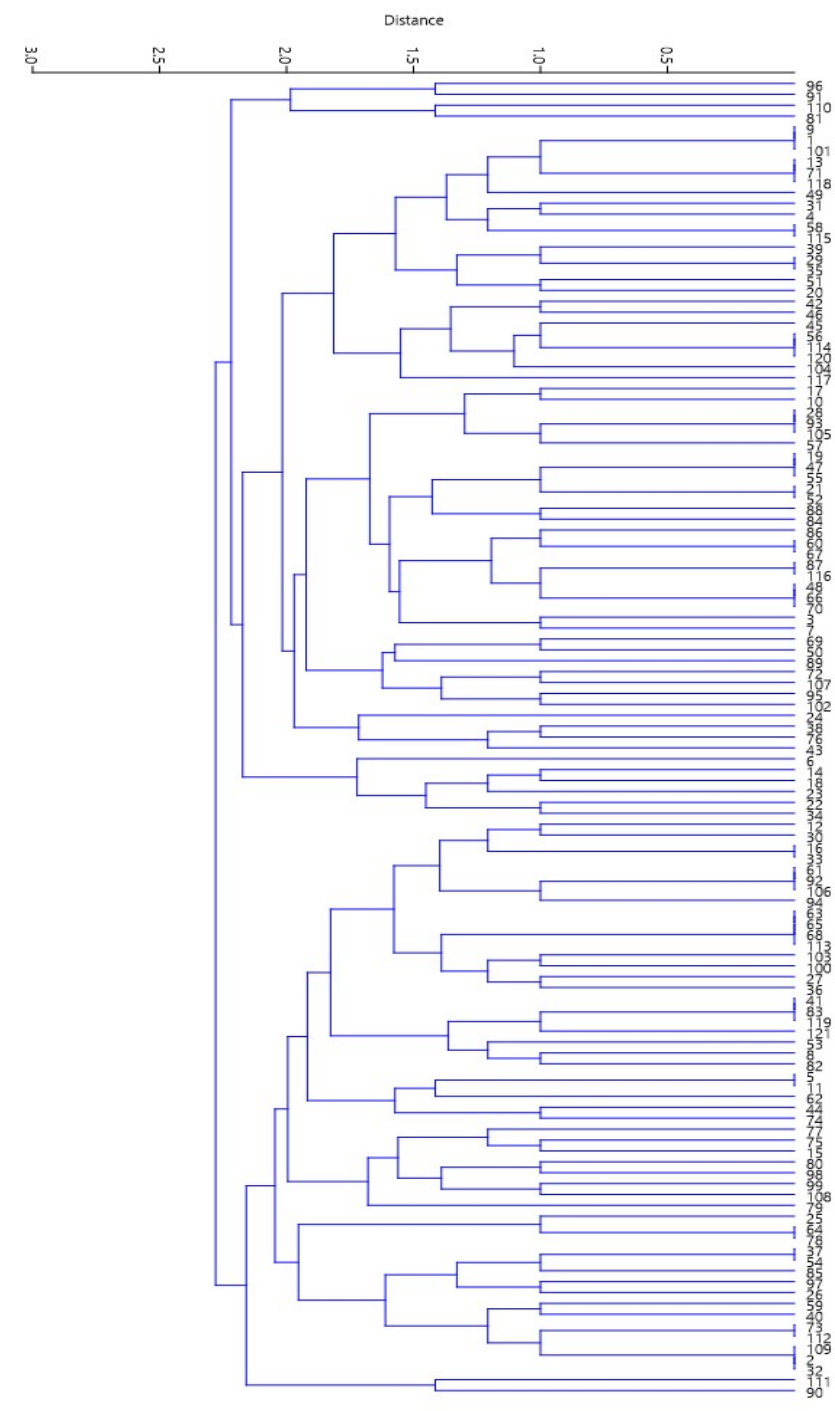

Fig. 3 : Dendogram showing genetic diversity among 121 RIL rice lines with polymorphic molecular markers using PAST software version $2.17 \mathrm{C}$

IIA2.2.Similarly, 32 genotypes which exhibited strong dormancy upto 10 days after harvesting and grouped in cluster 1under $\mathrm{D}^{2}$ analysis were also divided into $5 \mathrm{sub}$ clusters in molecular diversity. Eswar Rao et al. (2017) also reported similar findings in a study of 50 rice genotypes. 
Morphological \& molecular characterization of recombinant inbred lines for dormancy related traits in rice

\begin{tabular}{|c|c|c|c|c|c|}
\hline Cluster & & Sub clu & & $\begin{array}{l}\text { Total no. } \\
\text { of lines }\end{array}$ & Designation of the lines \\
\hline \multirow[t]{3}{*}{ I } & IA & & & 2 & SD 111, SD90 \\
\hline & IB & IB1 & & 15 & $\begin{array}{l}\text { SD25, SD64, SD78, SD37, SD54, SD85, SD97, SD26, SD59, SD40, SD73, SD112, SD109, } \\
\text { SD2, SD32 }\end{array}$ \\
\hline & & IB2 & & 36 & $\begin{array}{l}\text { SD12, SD30, SD16, SD33, SD61, SD92, SD106, SD94, SD63, SD65, SD68, SD1 13, } \\
\text { SD103, SD100, SD27, SD36, SD41, SD83, SD119, SD12 1(MTU 100 1), SD53, SD8, SD82, } \\
\text { SD5, SD11, SD62, SD44, SD74, SD77, SD75, SD15, SD80, SD98, SD99, SD108, SD79 }\end{array}$ \\
\hline \multirow[t]{4}{*}{ II } & IIA & IIA1 & & 6 & SD6, SD14, SD18, SD23, SD22, SD34 \\
\hline & & IIA2 & IIA2.1 & 34 & $\begin{array}{l}\text { SD17, SD10, SD28, SD93, SD105, SD57, SD19, SD47, SD55, SD21, SD52, SD88, SD84, } \\
\text { SD86, SD60, SD67, SD87, SD116, SD48, SD66, SD70, SD3, SD7, SD69, SD50, SD89, } \\
\text { SD72, SD10, SD95, SD 102, SD 24, SD 38, SD 76, SD43 }\end{array}$ \\
\hline & & & IIA2.2 & 24 & $\begin{array}{l}\text { SD9, SD1, SD1 01, SD13, SD71, SD1 18, SD49, SD3 1, SD4, SD58, SD115, SD39, SD29, } \\
\text { SD35, SD51, SD20, SD42, SD46, SD45, SD56, SD1 14, SD120 (BPT 2231), SD104, SD117 }\end{array}$ \\
\hline & IIB & & & 4 & SD96, SD91, SD110, SD81 \\
\hline
\end{tabular}

\section{Conclusion:}

Among the RIL population under study, the lines viz., SD 3, SD 12, SD 15, SD 68, SD 72, SD 87 and SD 113 which were categorized as strongly dormant upto 10 days after harvesting also exhibited similar banding pattern with the dormant parent MTU 1001 when amplified with more than two markers under genotyping. Hence, all these lines can be utilized as promising cultures/donors in future breeding programmes.

\section{Acknowledgment:}

I am (author) submitting my own research work paper and conclusion mentioned in the paper were drawn based on the results got out of research work.

\section{REFERENCES}

Bharathi, G., Krishnaveni, B., Neeraja, C.N., Ahamed, M.L. and Lalitha, K.J. (2019). Validation of reported markers for seed dormancy and pre-harvest sprouting resistance in rice (Oryza sativa. L). Journal of Pharmacognosy and Phytochemistry, 2: 103-108.

Cai, H.W. and Morishima, H. (2000). Genomic regions affecting seed shattering and seed dormancy in rice. Theoretical and Applied Genetics, 100: 840-846.

Doyle, J.J and Doyle, J.L. (1990). Isolation of plant DNA from fresh tissues. Focus.,12: 13-15.

Eswar Rao, R., Krishnaveni, B., Kumar, P.V.R and Rao, S. (2017). Morphological and molecular diversity in rice (Oryza sativa L.) genotypes. Journal of Rice Research, 10(2): 1-6
Hedge, J.E. and Hofreiter, B.T. (1962). In: Carbohydrate Chemistry 17 (Eds Whistler, R. L and Be Miller, J. N) New York, Academic Press.

Kuma, K., Shinde, S.R. and Jagtap, S.M. (2015). Genetic divergence in upland rice (Oryza sativa L.). International Journal of Plant Sciences, $10: 60-63$.

Li, B. and Foley, M.E. (1997). Genetic and molecular control of seed dormancy. Trends in Plant Science, 2: 384-389.

Mahalanobis, P.C. (1928). A statistical study at Chinese head measurement. Journal of Asiatic Society of Bengal, 25: 301307.

Monohara, K.R. and Singh, N.P. (2013). Genetic divergence among rice landraces of Goa. Oryza, 50 : 100-104.

Moore, S. and Stein, W.H. (1948). In: Methods in Enzymology (Eds. Colowick, S. P and Kaplan, N. D) New York, Academic Press.

Pervaiz, Z.H., Rabbani, A.M., Khaliq, I., Pearce, S.R. and Salman, A.M. (2010). Genetic diversity associated with agronomic traits using microsatellite markers in Pakistani rice landraces. Electronic Journal of Biotechnology, 13 (3): 0717 3458.

Seshu, D.V. and Sorrells, M.E. (1986). Genetic studies on seed dormancy in rice. Rice Genetics Collection Collect, $\mathbf{1}$ : 369-382.

Sunayana, R. and Sarma, R.N.(2012). Molecular diversity in indigenous rice land races of Assam. Indian Journal of Biotechnology, 11: 23-29.

Virk, P.S., Ford-Lloyd, B.V., Jockson, M.T. and Newbury, H.J. (1995). Use of RAPD for the study of diversity within plant 
D. B. K. V. Mani, B. Krishna Veni, V. Roja and S. N. Umar

germplasm collections. Heredity, 74: 170-179.

Voleti, S.R., Rao, R., Jyothi, B., Subrahmanyam, D., Prasad, S.S., Swamy, K.N. and Vikranth, B.C. (2013). Grain shattering and dormancy in rice. Techical Bulletin, 67: 52.
Wan, J., Nakazaki, T., Kanaura, K. and Ikehashi, H. (1997). Identification of marker loci for seed dormancy in rice (Oryza sativa L.). Crop Sci.,37: 1759-1763.

$17^{\text {th }}$ Year

$\star \star \star \star \star$ of Excellence $\star \star \star \star \star$ 